${ }^{1}$ TASSARA ANDRADE, Pilar. Programas de desarrollo rural y patrimonio: El impacto de los fondos europeos en Andalucía. EN Jornadas Andaluzas de Difusión (6ª ${ }^{a}$ 2001. Málaga). Sevilla: Junta de Andalucia, Consejería de Cultura, 2002

${ }^{2}$ Presupuesto de la Junta de Andalucia para el año 2002

e iniciativas públicas o privadas de contenido indiscutiblemente patrimonial. De esta cantidad, a la que habría que sumar lo invertido en patrimonio por el programa Proder, un 43\% se invirtió en equipamientos e infraestructuras (museos, centros de documentación, centros de interpretación, etc.); un 23\% a la puesta en valor (señalización, alumbrado, mejora de caminos, etc); un $20 \%$ a la rehabilitación (recuperación de ermitas, puentes, molinos, murallas, etc.); un 10\% a la difusión (guías, publicaciones, jornadas, seminarios, etc.); y un $4 \%$ a la investigación (estudios, inventarios, etc.). Como referencia, el año 2002, la Consejería de Cultura había invertido dentro del programa de Bienes Culturales un total de 29 millones de euros para el conjunto de Andalucia ${ }^{2}$, buena parte de los cuales han ido a parar a las zonas menos rurales de nuestra comunidad.

Analizando los proyectos patrimoniales apoyados por ambos programas, encontramos muy pocos ejemplos de planes territoriales de interpretación del territorio que permitan ordenar la oferta cultural y turística, que incorporen instrumentos de control y de gestión de los flujos turísticos, que tengan en cuenta la capacidad de carga cultural del territorio, que se preocupen por la viabilidad económica (centros de interpretación flamantemente inaugurados están ahora cerrados por falta de presupuesto) y que entiendan que forman parte de una realidad cultural más amplia. En cambio, sí abunda, como receta cultural de éxito, el binomio museo etnológico-molino/almazara, al que hay que añadir, si procede, la Sala o Centro de Interpretación que los Parques Naturales reparten entre sus municipios como incomprensible disculpa y compensación por ayudarles a conservar los recursos naturales que los hacen atractivos. Destacando el aumento en el nivel museológico y museográfico que se ha conseguido en los

Inversiones LEADER II

Investigación

Rehabilitación

P. en valor

Difusión

Equipamientos

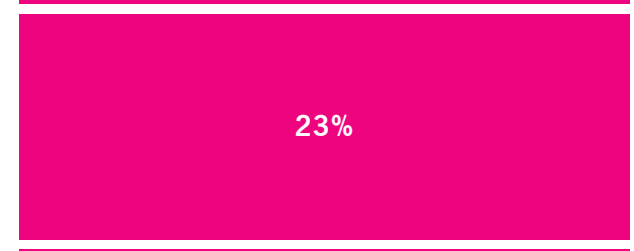

$4 \%$
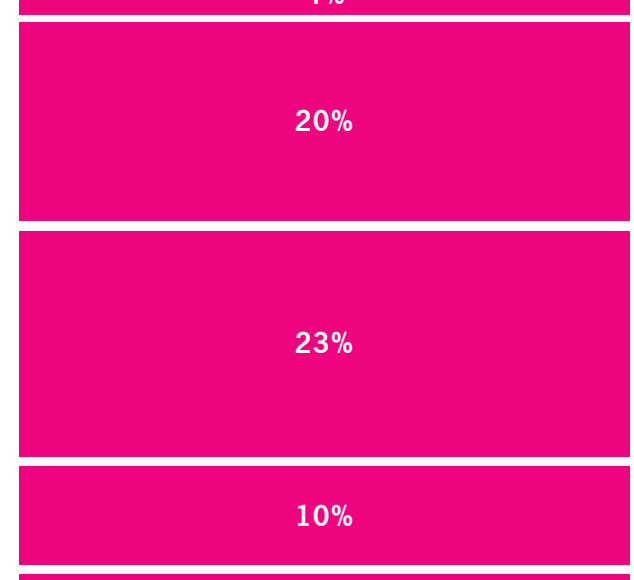

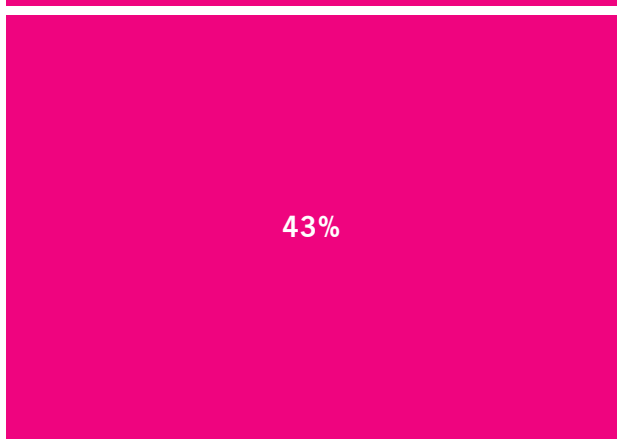

diez últimos años en Andalucía, tendríamos que hacer un esfuerzo por encontrar soluciones más imaginativas y novedosas que ayuden a propios y foráneos (por este orden) a entender el importante legado cultural del que somos depositarios. Soy de la opinión de que sólo se entiende lo que se siente y de que lo no se entiende simplemente no interesa, por lo que la identidad cultural andaluza depende en buena parte de nuestra capacidad de hacer sentir nuestro patrimonio a las futuras generaciones.

Sin entrar en discusiones estériles sobre quién está invirtiendo realmente en el patrimonio cultural de los pueblos, lo cierto es que existe una importante aportación de recursos económicos, que se están gestionando por los cincuenta grupos de desarrollo existentes en Andalucía bajo la tutela de la Consejería de Agricultura y

\title{
Voces
}

\section{Patrimonio y desarrollo local: sí, pero...}

José Castillo Ruiz

Profesor Titular Historia del Arte. Universidad de Granada

Vincular, hoy en dia, Patrimonio y desarrollo, especialmente si se añaden adjetivos como sostenible, local o solidario, constituye, tanto en el ámbito del pensamiento como de la praxis administrativa, una garantía de atención, éxito, progreso o modernidad.

Pues bien, aun partiendo, como premisa, de que la consecución de beneficios económicos a través de la acción patrimonial me parece legítima, tengo que manifestar que, al igual que sucedió con los centros históricos en las décadas de los setenta y ochenta, la orientación productiva de la tutela puede resultar paralizante para el conjunto de bienes que integran el Patrimonio, dada la desmesura de las responsabilidades atribuidas al mismo bajo esa consideración. Hacer depender, más o menos directamente, del aprovechamiento productivo de los "recursos patrimoniales" la satisfacción de exigencias sociales irrenunciables como el reequilibrio territorial de una región, el desarrollo sostenible de una zona determinada o la vertebración o integración social de la misma, puede resultar, sino se redimensionan adecuadamente estos objetivos, muy peligroso para la continuidad histórica del Patrimonio, ya que son tan absolutamente legitimas esas necesidades sociales que ni siquiera la imposibilidad material y valorativa de los propios recursos (la imposibilidad, por ejemplo, de dar cabida a más turistas en un determinado monumento o la de incorporar una función altamente productiva en un inmueble incompatible con dicho uso) resulta suficiente para impedir o anular su consecución.

No deja de ser curioso, en este sentido, que las necesidades vitales del hombre, cuya consideración -aunque no en la dimen- $\gg \gg$ 


\section{$090-091$ \\ Debate \\ e Investigación}

Patrimonio y desarrollo

rural en Andalucía

\section{PH42 - Febrero 2003}

Pesca sin el control y, muchas veces, sin siquiera el conocimiento de la propia Consejería de Cultura (sobre todo en las intervenciones para las que no se requiere un informe preceptivo de la correspondiente delegación provincial de esta Consejeria). El problema se encuentra no tanto en el plano económico en el que la Consejería de Agricultura y Pesca ha demostrado su solvencia sino en el plano cultural, para lo cual no dispone de los recursos humanos necesarios para acompañar los procesos de investigación, conservación y puesta en valor del patrimonio comarcal andaluz.

Se ponen de manifiesto pues dos carencias directamente atribuibles al conjunto de administraciones del estado, de las que no escapa nuestra administración regional. Se trata, por un lado, de la ausencia de medidas transversales, o de cooperación interdepartamental o simplemente un marco institucional que defina las relaciones que deberían existir, en nuestro caso, entre la Consejería de Agricultura y Pesca y la de Cultura y, por el otro, la inexistencia de una evaluación adecuada de las intervenciones públicas y privadas asociadas a los programas de desarrollo como Leader o Proder.

Respecto a estos procesos de seguimiento y evaluación, es evidente una creciente implicación en el control y fiscalización de dichos programas por parte de la Consejería de Agricultura y Pesca como ha quedado de manifiesto en los decretos 7/2002 y 8/2002, del 15 de enero, que regulan los programas Proder de Andalucía y Leader Plus, respectivamente. Si anteriormente en los programas Leader, Leader II y Proder eran los grupos competentes para decidir los proyectos a subvencionar, a pesar de la intervención económica de un organismo público y del papel consultivo de la delegación provincial de la Consejería, en los nuevos programas esa decisión final se traslada de manera vinculante a las delegaciones provinciales lo que previsiblemente se traducirá en una menor agilidad en la gestión y un progresivo distanciamiento de los grupos de desarrollo con las dinámicas y tiempos del territorio. Por otro lado, estos procesos de seguimiento y evaluación, se están centrando cada vez más en los aspectos administrativos y económicos del programa que, hasta la fecha, no han ido más allá de la comprobación "in situ" de la existencia real de las inversiones justificadas. Se echa de menos por parte de esta consejería, como organismo coordinador de ambos programas en Andalucía o incluso del propio Observatorio Leader de ámbito europeo, un mayor interés por la idoneidad del modelo de desarrollo comarcal, por las medidas de conservación del medioambiente, por el nivel de participación de la población y, también, por la solvencia cultural de las propuestas patrimoniales. Teniendo en cuenta que para la nueva etapa de los programas Proder y Leader el patrimonio será uno de los aspectos aglutinantes (prioritarios), tal vez la Consejería de Cultura, libre de las farragosas responsabilidades directas sobre los programas y de común acuerdo con la Consejería de Agricultura y Pesca, podría implicarse más en el día a día del desarrollo cultural de las comarcas andaluzas, creando un observatorio que asesorara la puesta en valor del patrimonio, que apoyara la inscripción de nuevos elementos en el catálogo de bienes culturales, que asegurara un mayor respeto hacia las técnicas constructivas tradicionales, que financiara programas específicos de intervenciones arqueológicas y que contribuyera a dar, en definitiva, esa visión cultural de conjunto tan difícil de obtener desde la perspectiva de la Consejería de Agricultura y Pesca y desde los grupos de desarrollo.

Precisamente esa ausencia de visión de conjunto está llevando algunas apuestas patrimoniales locales al límite de su viabilidad. sión económica ahora tan resaltada- como sustentadoras de los valores patrimoniales supuso el inicio de la Protección como disciplina científica (Aloïs Riegl como principal artífice), pudieran acabar "devorando" a los objetos sobre los que pretendian evaluarse $y$, muy especialmente, regenerarse.

Por tanto, hay que admitir y apoyar cualquier cambio en la finalidad tutelar que obedezca a la historicidad propia de la disciplina, pero desde la continuidad e integración en los fundamentos tutelares que otorgan cientificidad a la misma y que han sido fruto de una larga maduración histórica. Esto implica no renunciar a principios indiscutibles como la superioridad de la autenticidad cultural del bien (prescindir de valores relevantes de un bien para potenciar la capacidad productiva del mismo, supone desistir de su propia consideración patrimonial), la prevalencia de la acción pública (otorgar una participación elevada a los agentes privados acogiéndose a argumentos "fraudulentos" como la necesidad financiera o el aumento de la participación social, supone diluir la contundencia de una premisa irrefutable: el Patrimonio existe y se funda en la exis- tencia de un interés público y social) o la planificación global y conjunta de todos los bienes patrimoniales (administrar localmente el patrimonio de una zona supone discriminar a aquellos ciudadanos que, amparados en la universalidad de los valores culturales, reclaman una acción conjunta y unitaria de todos los bienes por encima de abstractas, circunstanciales y fragmentadas fronteras administrativas). 